\title{
Physiological roles and pathological involvement of protease activated receptors in renal diseases: Therapeutic advances and challenges
}

\author{
Newly Bagang ${ }^{1}$, Kirti Gupta ${ }^{2}$, Sidharth Mehan ${ }^{3}$, and Gaaminepreet Singh ${ }^{4}$ \\ ${ }^{1}$ Arunachal University of Studies \\ ${ }^{2}$ Maharishi Markandeshwar University \\ ${ }^{3}$ ISF College of Pharmacy \\ ${ }^{4}$ Chitkara University
}

December 29, 2021

\begin{abstract}
Studies have demonstrated that protease activated receptors (PARs) with four subtypes (PAR1-4) are mainly expressed in the renal epithelial, endothelial and podocyte cells. Evidently, the PAR-1 and PAR-2 have shown differential therapeutic outcomes in rodent models of type- 1 and type-2 diabetic kidney diseases due to distinct etiological basis of each disease type. Both PAR-1 and PAR-2 blockers/knock-out have abolished the drug-induced nephrotoxicity in rodents by suppression of tubular inflammation and fibrosis. Notably, PAR-2 inhibition was found to improve autophagy in the urethral obstruction model. Only the PAR-1/4 subtypes have emerged as a therapeutic target for the treatment of experimentally induced nephrotic syndrome where their respective antibodies attenuated the podocyte apoptosis. So far the PAR-2/PAR-4 subtypes involvement has been tested in sepsis acute kidney injury and renal ischemia-reperfusion model. This review discusses the existing gaps, therapeutic advances and future perspectives related to the roles of different PARs in kidney diseases.
\end{abstract}

Physiological roles and pathological involvement of protease activated receptors in renal diseases: Therapeutic advances and challenges

\section{Newly Bagang ${ }^{1}$, Kirti Gupta ${ }^{2}$, Sidharth Mehan ${ }^{3}$, Gaaminepreet Singh*}

${ }^{1}$ Department of Pharmacy, Arunachal University of Studies, Knowledge city, NH-52, Namsai, Arunachal Pradesh, India. Email: newlybagang@gmail.com

2 MM College of Pharmacy, Maharishi Markandeshwar Deemed to be University, Mullana, Ambala (Haryana), India. Email: kirtigupta17397@gmail.com

${ }^{3}$ Department of Pharmacology, Indo-Soviet Friendship College of Pharmacy, Moga (Punjab), India. Email: sidh.mehan@gmail.com

4* Chitkara College of Pharmacy, Chitkara University, Punjab, India. Email: gpsinghcologist@hotmail.com

${ }^{*}$ Corresponding author

Dr. Gaaminepreet Singh

Associate Professor,

Chitkara College of Pharmacy, 
Chitkara University,

Chandigarh-Patiala National Highway (NH-64)

Tehsil-Rajpura, District-Patiala-140401, Punjab, India

Gaamine.singh@chitkara.edu.in

gpsinghcologist@hotmail.com

\section{Abstract}

Studies have demonstrated that protease activated receptors (PARs) with four subtypes (PAR1-4) are mainly expressed in the renal epithelial, endothelial and podocyte cells. Evidently, the PAR-1 and PAR-2 have shown differential therapeutic outcomes in rodent models of type-1 and type-2 diabetic kidney diseases due to distinct etiological basis of each disease type. Both PAR-1 and PAR-2 blockers/knock-out have abolished the drug-induced nephrotoxicity in rodents by suppression of tubular inflammation and fibrosis. Notably, PAR-2 inhibition was found to improve autophagy in the urethral obstruction model. Only the PAR$1 / 4$ subtypes have emerged as a therapeutic target for the treatment of experimentally induced nephrotic syndrome where their respective antibodies attenuated the podocyte apoptosis. So far the PAR-2/PAR-4 subtypes involvement has been tested in sepsis acute kidney injury and renal ischemia-reperfusion model. This review discusses the existing gaps, therapeutic advances and future perspectives related to the roles of different PARs in kidney diseases.

Keywords: Protease activated receptors (PARs), diabetic kidney disease (DKD), diabetic nephropathy (DN), acute kidney injury (AKI), diabetes mellitus (DM), endogenous proteases, endothelial nitric oxide synthase (eNOS)

\section{Abbreviations}

PARs- Protease activated receptors

I/R- Ischemia reperfusion

AKI- Acute kidney injury

PASD- Periodic acid- Schiff diastase

WT- Wild type

KIM-1- Kidney injury molecule-1

MCP-1- Monocyte chemoattractant protein-1

UUO- Unilateral ureteral obstruction

TEM- Transmission electron microscopy

LC3-II- Light chain 3-II

HE- Hematoxylin and eosin staining

PAN- Puromycin aminonucleoside

NS- Nephrotic syndrome

DIN-Drug induced nephropathy

ESRD-End stage renal disease

TF-Tissue factor

PLA- Proximity ligation assays 
ERK- Extracellular signal-regulated kinase

RT-PCR- Real-Time polymerase chain reaction

IHC- Immunohistochemistry

eNOS- Endothelial NO synthase

uPA- Urokinase plasminogen activator

uPAR- Urokinase plasminogen activator receptor

PTC-Proximal tubule cells

\section{Introduction}

PARs are cell surface receptors, of the family G-protein- coupled receptors (GPCRs) with extracellular amino terminus domain, and consisting of four identified subtypes namely; PAR1, PAR2, PAR3, and PAR4 [1-3]. Although the pathological role of PAR1 and PAR2 is well described in certain experimental kidney injury models, less information is available on PAR3 and PAR4. Notably, some endogenous proteases such as trypsin, tryptase, cathepsin, urokinase, and kallikreins are activators of PARs that regulate renal homeostasis, inflammation, and tissue remodeling as both are interlinked with the pathogenesis of acute kidney injury (AKI) [4-8]. Similarly, during disease conditions such as sepsis-induced glomerulonephritis or septic shock, PARs can also be activated by clotting factors namely thrombin, FVIIa, and FXa. These pathological conditions might involve hyper-coagulability, and inflammation which can lead to clotting factordependent up-regulation of PAR receptor expressions and this further induce(s) glomerular fibrin deposition and macrophage infiltration [9-10]. Moreover, during the diseased conditions, activation of PARs by proteolytic cleavage at the extracellular amino terminus domain results in the formation of tethered ligand. Later, this newly formed tethered ligand binds to the receptor body and can activate the transmembrane signaling molecules involving MAPKs, NF-kB and PI3K/AKT/mTOR, which are responsible for producing various pathophysiological responses such as mesangial cell proliferation, extracellular matrix production, renal fibrin deposition, podocyte apoptosis and also necrosis in kidney disease [1-3, 11-14]. Both PAR1 and PAR2 subtypes are expressed in the kidney and known to promote fibro-proliferative disorders and exacerbate diabetic nephropathy (DN) [6, 15-18]. Additionally, PAR1 and PAR2 are also responsible for initiating podocyte cell injury, tubular epithelial cell inflammation and mesangial cell expansion in the kidney [5, 19, 20]. Moreover, few studies have reported that the PAR2 receptor subtype contributes to the progression of kidney damage in cisplatin and also IgA-induced nephropathy, which suggests the disease's specific involvement of particular subtypes [21-23]. This review summarizes the various findings which have tested the role of PAR's in the pathophysiology of kidney diseases, provides in-depth insights into the mechanisms and discusses the standing challenges in therapeutic testing of these receptor subtypes in kidney diseases.

A PubMed based literature survey was performed using the following phrases in all possible combinations mainly: "protease activating receptor subtypes in kidney diseases" (43 results), "role of PAR-1 in renal injuries" (09 results), "role of PAR-2 in kidney disease" (12 results), "role of PAR-3 in renal disease" (5 results), "PAR in glomerular and tubular injury" (10 results), "PAR in drug-induced nephrotoxicities" (27 results), "PAR in kidneys inflammation and fibrosis" (27 results), "effects of PAR in diabetic kidney disease" (25 results), "role of PAR 1 and PAR2 in ischemia injury in rats" (4 results) This survey resulted into a total of 162 published articles and after scrutinization only 13 original research evidence focused on the involvement of PARs in renal diseases, published between 1995-2021. The selected studies tested the role of different PAR subtypes in diverse renal injuries including ischemia-reperfusion injury, type I/II diabetic nephropathy, sepsis-induced acute kidney injury, nephrotic syndrome, biologicals based renal injury, obstructive injury, drug-induced nephrotoxicities, podocytopenia, in-vitro and ex-vivo findings, glomerular as well as tubular diseases. Evidence pertaining to the impact of PARs subtypes in co-morbidities, other organ injuries, and clinical manifestations were excluded from the present review.

\section{Evolutionary background of PAR subtypes}


The major breakthrough came in the 1990s when it was first discovered that in a wide variety of tissues some membrane-spanning proteins do exist on the cell surfaces and are known as protease-activated receptors (PAR) that belong to the G protein-coupled receptor family. In the year 1991, the first member of PAR receptors was identified and cloned known as protease-activated receptor-1 (PAR-1) [24]. To date, four members of PARs have been identified, of which PAR1, PAR3, and PAR4 are known as thrombin receptors, and on the other hand PAR2 is known as serine receptor [25]. Notably, a study in PAR1 knockout mice lead to the discovery of PAR3 and PAR4 receptors which showed a similar response to thrombin receptor on platelet as that of PAR1 [26]. In the later year, PAR2 was discovered serendipitously and was found to be activated only by a serine receptor protein called trypsin [25]. Presently Vorapaxar and atopaxar are available PAR-1 antagonists that have undergone extensive clinical development and are approved as antiplatelet agents [27].

\section{Expression of PARs in the kidneys}

In the kidneys, the expression of PAR1 and PAR2 is most abundant in contrast to that of other receptor subtypes [2, 28-30]. Previous in vitro studies using the RT-PCR technique have detected the transcripts of PAR1, PAR2, and PAR4 in both isolated endothelial and epithelial cells of humans and rodent kidneys. However, mRNA for PAR3 was found to be absent in two of these studies [2, 29]. The PAR receptors are endogenously activated by serine proteases which are also part of the clotting system, where thrombin is responsible for PAR1, PAR3, PAR4 activation, and trypsin activates PAR2. Moreover, some urinary proteases including urokinase, kallikrein can also activate PAR1 and PAR2 and have been summarized in table $1[1,2,28]$. The Urokinase enzyme is also called a urokinase plasminogen activator (uPA). It is synthesized in the kidneys by proximal and distal tubular epithelial cells and is secreted in the urine. Other sources which also synthesize urokinase are monocytes (macrophages), fibroblast, and myofibroblasts [31,32]. Moreover, it is believed that urokinase is released during inflammation or injury as confirmed by experimental studies in mice [33]. This study showed that mRNA expression of urokinase plasminogen activator receptor (uPAR) was absent in normal kidneys whereas, it was up-regulated in the kidneys of UUO induced chronic kidney injury in mice. Another urinary protease, kallikrein is also released in the kidneys from the distal convoluted tubular cells and secreted into the urine. It is also reported that renal kallikrein plays an important role in the regulation of renal hemodynamics and in glomerular filtration [34,35]. Moreover, the up-regulation of tissue factor upon injury or inflammatory state leads to activation of PAR1 and PAR2 by involving FXa $[36,37]$, which subsequently, activates various signaling pathways including PKC, MAPK, $\mathrm{NF}-\mathrm{kB}$, thus making PARs responsible for triggering several inflammation processes $[4,12,13]$. Eventually, the activation of these signaling molecules increases the release of pro-inflammatory markers such as TNF- $\alpha$, IL-1 $\beta$, IL-6/8; which alter the renal hemodynamics including GFR and also fluid reabsorption $[4,13,29,37]$. Apart from endogenous proteases and FXa, there are some synthetic peptide activators of PAR1 (TRAP-6, TFLLR-NH2) and PAR2 (SLIGKV-NH2, SLIGL-NH2) [2, 38], and an endogenous protein called activated protein C (APC) which also acts as an agonist for both PAR1 and PAR2 [4, 36, 39].

Table.1: A summary of PAR activators

\begin{tabular}{|c|c|c|c|c|c|}
\hline Activators & PAR1 & PAR2 & PAR3 & PAR4 & Reference \\
\hline Serine proteases & $\begin{array}{l}\text { Thrombin, } \\
\text { cathepsin G }\end{array}$ & $\begin{array}{l}\text { trypsin, } \\
\text { tryptase, } \\
\text { cathepsin S }\end{array}$ & Thrombin & $\begin{array}{l}\text { Thrombin, } \\
\text { cathepsin G }\end{array}$ & $1,2,3,59$ \\
\hline $\begin{array}{l}\text { Urinary } \\
\text { proteases }\end{array}$ & Urokinase & $\begin{array}{l}\text { Kallikrein- } \\
2,4,5,6\end{array}$ & & kallikrein-14 & $2,22,60,61$ \\
\hline $\begin{array}{l}\text { Coagulation } \\
\text { proteases }\end{array}$ & $\begin{array}{l}\text { FXa, APC, } \\
\text { TF-VIIa, } \\
\text { Plasmin }\end{array}$ & $\begin{array}{l}\text { FXa, TF-VIIa, } \\
\text { APC }\end{array}$ & $\mathrm{FXa}, \mathrm{APC}$ & $\begin{array}{l}\text { FXa, TFVIIa, } \\
\text { Plasmin }\end{array}$ & $3,59,60$ \\
\hline $\begin{array}{l}\text { Synthetic } \\
\text { peptides }\end{array}$ & $\begin{array}{l}\text { TRAP- } \\
6, \text { TFLLR-NH }\end{array}$ & $\begin{array}{l}\text { SLIGKV-NH } \\
\text { SGLGL-NH } \\
\text { SG }_{2}\end{array}$ & & $\begin{array}{l}\text { AYPGKF- } \\
\text { NH2 }\end{array}$ & 2,23 \\
\hline
\end{tabular}




\section{Physiological and pathophysiological role of PARs in kidney(s)}

Several studies have reported the physiological and pathophysiological role of PARs in the kidneys and the main study highlights include:

1) In the renal cortical collecting duct cells, PAR2 activation increases the intracellular calcium ion and regulates the calcium-dependent chloride secretion $[2,40]$.

2) Activation of PAR2 also regulates fluid reabsorption by facilitating sodium reabsorption in the cortical collecting duct cells, whereas it also prevents potassium secretion via activating the ERK pathway [29, 30, 41]. This was evident from the experimental study, which showed that administration of trypsin, which is a known activator of PAR2 induced sodium reabsorption in the cortical collecting duct cells of WT mice but was not observed in PAR2 ${ }^{-/-}$mice. Furthermore, based on the fact that the expression of ERK is up-regulated by the PAR2 activation, the mechanism involved was investigated, which revealed that phosphorylation of ERK is increased upon the activation of PAR2. Moreover, inhibition of ERK by U0126 significantly reduced the trypsin-dependent PAR2 induced sodium reabsorption. Additionally, potassium homeostasis was found to be regulated by PAR2 and potassium secretion was inhibited in cortical collecting duct cells of mice with trypsin-induced PAR2 activation [41].

3) PAR2 is also involved in the regulation of inflammation, cell growth and repair [30]. This was noticeable from the previous investigations [42-44], which showed that in primary cultures of human proximal tubule cells (PTC), activation of PAR2 by its activating peptide SLIGKV-NH $\mathrm{N}_{2}$ resulted in increased monocyte chemoattractant protein-1(MCP-1) levels, which is a pro-inflammatory molecule, and in together with its chemotactic actions, it also promotes inflammatory responses with the production of IL-6, IL-8 in the tubular cells. Additionally, activation of PAR2 also promotes the proliferation of epithelial and endothelial cells, thereby suggesting the role of PAR2 in cell growth and repair. [42-44].

4) The subtypes PAR1 and PAR2 are demonstrated to be involved in the regulation of renal hemodynamics. Notably, an in-vitro study using an isolated rat kidney perfusion model showed the opposite effects of PAR1 and PAR2 in the regulation of renal hemodynamics. The activation of PAR1 by agonist TFLLR or thrombin produced renal vasoconstriction and decreased both renal perfusion flow rate (RPF) and glomerular filtration rate (GFR), which was completely diminished by inhibition of protein kinase C. On the other hand, PAR2 activation by agonist, SLIGRL-NH2 or trypsin does not show any effect on the basal RPF (renal plasma flow) and GFR, but with the administration of angiotensin II (ANG II) prior to agonist treatment, abolished Ang-II induced vasoconstriction and resulted in renal vasodilation and improved GFR $[2,29]$. This indicates that PAR2 activation regulates renal perfusion by counteracting the Ang II effects on renal hemodynamics. During pathological conditions many proteases gets activated, which induce up-regulation in the expression of PARs, indicating that these receptors have a prominent pathological roles in the progression of kidney disease [29, 36]. Various experimental studies on PARs in kidney diseases have been summarized in table 2, and also flow diagram summarizing the pathophysiological role PAR receptors in kidney disease progression is shown in figure $1[37,45]$.

Table 2. A summary on the role of PARs in various kidney disease models

\begin{tabular}{lll}
\hline S.No & Experimental models & S \\
\hline 1 & PAR 1 deficient STZ induced diabetic nephropathy model in mice & $\mathrm{C}$ \\
2 & PAR1 inhibition in type-2 diabetic nephropathy model in mice & $\mathrm{B}$ \\
3 & eNOS deficient diabetic nephropathy model in mice & $\mathrm{C}$ \\
4 & Role of FXa and PAR2 interaction in diabetic nephropathy model in mice & $\mathrm{A}$ c \\
5 & Role of PAR 2 in STZ induced diabetic nephropathy model in mice & $\mathrm{C}$ \\
6 & Role of PARs in thrombin induced podocyte injury in NS (nephritic syndrome) model in rat & $\mathrm{B}$ \\
7 & Role of PAR1 in podocyte injury in doxorubicin induced nephropathy in mice model & $\mathrm{B}$ \\
8 & Role of PAR 2 in renal tubular epithelial inflammation in UUO mice model & $\mathrm{C}$ \\
9 & Role of PAR 4 in acute renal ischemia reperfusion injury induced AKI model in mice &
\end{tabular}




\begin{tabular}{lll}
\hline S.No & Experimental models & S \\
\hline 10 & Role of PAR2 in mediating focal segmental glomerulosclerosis in drug induced nephrotoxicity model & $\mathrm{N}$ \\
11 & Role of PAR2 blockade in mediating renal injury in a lipopolysaccharide (LPS) induced endotoxemic rat model & $\mathrm{N}$ \\
12 & Beneficial effect of PAR2 in VEGF inhibitor induced glomerular and podocyte injury in mice model & $\mathrm{C}$ \\
13 & Protective effects of dual blockade of PAR1 AND PAR2 in DKD & $\mathrm{e}$ \\
\hline
\end{tabular}

\section{Involvement of PAR's in progression of diabetic kidney disease}

Diabetic kidney disease is one of the most common complications in patients suffering from diabetes mellitus which may lead to chronic kidney disease (CKD) and end-stage renal disease (ESRD) $[3,12,46]$. Initially, in nephropathic conditions hyperglycemia leads to renal hemodynamic changes including abnormal substrate delivery (glucose, free fatty acid) for energy production in the mitochondria [2, 11, 47]. There is also an overproduction of electron donors NADPH and FADH2 which disturbs the electron transport chain in the mitochondria. As a result of mitochondrial dysfunction, there is increased reactive oxygen species (ROS) production which promotes oxidative stress resulting in podocyte and renal tubular cell apoptosis [46-48]. Moreover, hyperglycemic stress increases the production of inflammatory cytokines (TNF- $\alpha$, IL-6) resulting in glomerular changes including an increased proliferation of mesangial cells. The diabetic condition also results in afferent vasodilation and hyperaminoacidemia which promotes glomerular hyperfiltration and hyperperfusion. However, the high production of angiotensin-II at the efferent arteriole leads to vasoconstriction $[5,48,49]$. Notably, consistent vasoconstriction of efferent arteriole produces effacement of podocyte foot processes due to increased intraglomerular pressure and induces destruction of the glomerular filtration barrier which further leads to albuminuria [5, 49]. Evidence from earlier studies has suggested that both type-1 and type-2 diabetes conditions up-regulate thrombin generation [38]. Since thrombin is a PAR1 activator as mentioned above thus it is possible that PAR1 activation might play a key role in the development of glomerular injury in diabetic kidneys.

\section{Differential role of PARs in type 1 and type 2 diabetic kidney disease}

\subsection{Role of PAR1 in progression of diabetic nephropathy}

Experimental studies have suggested that PAR1 plays a pivotal role in diabetic kidney disease, where it is responsible for activation of fibroblast proliferation and extracellular matrix production resulting in progression of renal injury $[2,5]$. The pathological role of the PAR1 receptor has been investigated in both type-1 and type-2 diabetic animal models $[5,12]$. In the streptozotocin (STZ) induced type-1 diabetic mice model, the renal expression of PAR1 mRNA was higher in comparison to non-diabetic mice [4]. Subsequently, this study also revealed that cultured MES13 (mouse mesangial cells) cells exposed to high glucose medium showed higher transcripts of PAR1 than low glucose medium environment exposure. Furthermore, this study showed that in MES13 addition of thrombin resulted in the mesangial proliferation and fibronectin production mediated by PAR1 dependent activation of MEK and p38 signaling pathways. MEK and p38 are important components of the MAPK signaling pathway [50]. Interestingly, western blot analysis also showed that their expressions were higher in diabetic rats as compared to non-diabetic rats [51]. Moreover, studies have documented that MEK and P38 signaling are activated by high glucose levels, oxidative stress, and also inflammation and are responsible for various pathological events including cell proliferation, differentiation, and apoptosis, which further promote the progression of diabetic nephropathy [50,51]. Notably, in STZ induced type-1 diabetic mice model, the fibrin-mediated mesangial proliferation was abolished upon co-administration of PAR1 antagonist (p1pal-12) or by direct inhibition of MEK/p38 signaling indicating that thrombin and PAR1 are interlinked in the development of glomerular injury. Additionally, immunohistochemical evidence from PAR1 deficient diabetic mice showed a reduction in mesangial expansion, proliferation, fibronectin deposition, and also the absence of tubular atrophy compared to wild-type (WT) diabetic mice. Moreover, in WT diabetic mice increased plasma cystatin $\mathrm{C}$ levels and also proteinuria was observed due to hyperglycemia-induced hyperfiltration, podocyte apoptosis, and glomerular filtration barrier damage. So far studies have reported that the generation of plasma thrombin (PAR1 agonist) is increased in 
patients suffering from diabetes [52-54]. This evidence suggests that inhibition of thrombin-mediated PAR1 activation could be a novel therapeutic target for the prevention of type-1 diabetic nephropathy.

Another experimental study has tested the pathological involvement of PAR1 in the development of type-2 diabetic nephropathy [12]. BTBR ${ }^{\mathrm{ob} / \mathrm{ob}}$ mice are leptin-deficient obese mice that served as a diabetic group, whereas wild types (WT) are considered as a non-diabetic control group. BTBR ${ }^{\mathrm{ob} / \mathrm{ob}}$ diabetic mice were treated with vorapaxar, a PAR1 antagonist which produced an increased body weight. In this study, the type-2 diabetic mice exhibited renal pathological changes such as increased kidney weight, albuminuria, neutrophil-gelatinase-associated lipocalin (NGAL) excretion, and also increased plasma insulin levels. Moreover, BTBR ${ }^{\mathrm{ob} / \mathrm{ob}}$ diabetic mice showed glomerular injury with mesangial expansion, capillary dilation, and glomerulosclerosis. Notably, vorapaxar treatment did not correct the glomerular damage, but mesangial expansion was significantly reduced in comparison to non-treated diabetic BTBR ${ }^{\mathrm{ob} / \mathrm{ob}}$ mice. During the disease progression in $\mathrm{BTBR}^{\mathrm{ob} / \mathrm{ob}}$ mice, diabetic nephropathy was accompanied by inflammation as illustrated by increased IL-6, IL-1 $\beta$, TNF- $\alpha$, and MCP-1 in both vorapaxar treated and non treated diabetic mice. Importantly, these findings are in contrast to a previous study in which inhibition of PAR1 receptor prevented nephropathy in type 1 diabetes model [55]. The most reasonable explanation for distinct outcomes observed due to PAR1 blockade in the above studies could be based upon etiological differences in the development of type 1 and type 2 diabetic kidney diseases. In diabetic nephropathy, both hemodynamic and structural changes are interlinked with each other. Studies showed that in type-1 diabetic nephropathy, the earliest hemodynamic abnormality observed is renal hyperfiltration which leads to increased intra-glomerular pressure, followed by glomerular injury with podocyte effacement and also tubular dilation. These pathological events are also accompanied by microalbuminuria and a progressive decline in glomerular filtration rate (GFR) [56]. However, type-2 diabetic nephropathy is an inflammatory prominent disease, where other pathogenic factors including obesity, hypertension with compensatory hyperinsulinemia could exacerbate the metabolic disturbance [57]. Moreover, renal hypertrophy is observed post-development of glomerulosclerosis and tubulointerstitial fibrosis in DN (diabetic nephropathy). Of note, hemodynamic changes are commonly observed in both type 1 and 2 DN patients [58]. Thus it might be possible that PAR 1 inhibition could not influence the pathological manifestations accompanying the type-2 DN due to the complex etiological basis of this disease type. However, in type $1 \mathrm{DN}$, the PAR 1 inhibition exhibited renoprotection by improving renal dysfunction and ameliorating proliferative changes in glomerular regions.

\subsection{Involvement of PAR2 in progression of diabetic nephropathy}

After PAR1, the expression of PAR2 was found to be abundant in kidneys [2, 28-30]. The activity of PAR2 is tissue factor (FXa) dependent [36, 27, 59,60] and its activation exacerbates the renal tissue injury [61, $62]$. Furthermore, a study has demonstrated the involvement of tissue factor-mediated inhibition of eNOS signaling as the pathological mechanism responsible for the progression of diabetic nephropathy [63]. In this study both $\mathrm{eNOS}^{-/}$and WT mice were made diabetic by 5 consecutive i.p injections of low-dose STZ $(40 \mathrm{mg} / \mathrm{kg})$. It was observed that after 5 weeks of diabetes induction, the kidneys of $\mathrm{eNOS}^{-/}$mice showed higher tissue factor (TF) mRNA expression than the kidneys of WT diabetic mice, thereby suggesting the eNOS deficiency mediated up-regulation of TF expression. Additionally, immunohistochemical analysis revealed that in kidneys of $\mathrm{eNOS}^{-/-}$mice, tissue factor is mainly expressed in the macrophages which involved the kidney glomeruli. Moreover, the mouse mesangial cell line (CRL-1927) showed increased inflammation upon treatment with mouse factor VIIa as depicted by an increase in monocyte chemoattractant protein1(MCP-1) levels, which suggests the TF dependent activation of inflammation. Notably, in this study renal disease was exacerbated in high fat (HF) diet-fed $\mathrm{eNOS}^{-/-}$diabetic mice which lead to TF up-regulation, and development of functional and morphological changes in the kidneys as marked by an increase in urinary albumin, thickening of glomerular basement membrane (GBM), glomerulosclerosis, fibrin deposition, and also increase in various inflammatory and fibrogenic genes such as IL-6, TNF- $\alpha$, MCP-1, TGF- $\beta$ and type IV collagen expression. However, the administration of the anti-TF antibody, AF3178 has significantly reduced these manifestations in the kidney of $\mathrm{HF}$-fed $\mathrm{eNOS}^{-/-}$diabetic mice. Therefore, these findings suggest that lack of eNOS and subsequent TF up-regulation is responsible for the development and progression of DN in additional fat-fed eNOS ${ }^{-/-}$diabetic mice by promoting inflammation. However, it needs to be determined 
whether direct inhibition of PAR2 could exhibit similar renoprotective effects in eNOS-/- diabetic mice.

More studies have been performed to find out the pathological role of coagulation factor Xa and PAR2 interaction in experimental type-2 diabetic nephropathy model using Akita mice [59]. In diabetic Akita mice, mutation of insulin 2 gene results in pancreatic $\beta$-cell destruction and hyperglycemia, followed by insulin resistance and metabolic disturbance along with the development of albuminuria. Notably in this study, the $\mathrm{eNOS}^{-/-}$mice showed higher plasma FXa levels as compared to $\mathrm{NOS}^{+/+}$mice, regardless of the status of DM. Furthermore, this study also showed that in diabetic conditions, carbonyl stress was elevated in the peritoneal macrophages, which further up-regulated the expression of FXa in the peritoneal macrophage. Moreover, in eNOS ${ }^{-/-} \mathrm{DM}$ mice macrophage infiltration increased rapidly in the glomeruli and co-localized with FXa that lead to glomerular damage and nephropathy. Further inhibition of FXa by edoxaban retarded the invasion of macrophages in glomeruli of both $\mathrm{eNOS}^{+/-}$and $\mathrm{eNOS}^{-/-}$mice and resulted in amelioration of diabetic nephropathy as observed by a reduction in urinary albumin excretion, mesangial matrix production along with a reduction in PAR2 mediated inflammation evidenced by decreased expression of pro-inflammatory cytokines (Tgfb, Tnf- $\alpha$ ), and profibrotic genes (Pai1, Col1). Similarly, knockout of $\mathrm{PAR}^{-/-}$gene in AKITA mice with reduced FXa expression attenuated diabetic nephropathy by suppressing the release of inflammation. This finding suggested that clotting FXa dependent PAR2 activation promotes DN by inducing glomerular macrophage infiltration and inflammation.

Similarly, the impact of PAR2-/- knockout on the development of renal injury has been evaluated in streptozotocin-induced type-1 diabetic mice [64]. In this study, type-1 diabetes was induced by five consecutive injections of STZ at a dose of $50 \mathrm{mg} / \mathrm{kg}$ body weight. Six months after diabetes induction in PAR2 deficient mice reduced albuminuria was observed, but it was accompanied by glomerular injury as marked by increased mesangial expansion and collagen deposition in the glomeruli. In this case, these findings are opposite to the glomerular outcomes observed in PAR2 deficient type-2 diabetic Akita mice [59]. Further, histological analysis showed that PAR2 deficiency did not influence the podocyte number, and strikingly multiplex ligation-dependent probe amplification (MLPA) analysis using apoptosis, inflammation, and coagulation gene panels, showed increased expression of other subtypes PAR1 and SERPINE1 genes in PAR2 deficient diabetic mice as compared to wild type diabetic mice. SERPINE1 is a gene, encoding for plasminogen activator inhibitor 1(PAI-1), which belongs to the family of serine protease inhibitors, and regulates controlled blood clot resolution. Notably, the increasing compensatory level of PAR1 transcription in PAR2 deficient type-1 diabetic mice might be one of the possible reasons for the increased mesangial expansion in these d/iabetic mice. Certainly, it could be concluded from these findings that the PAR2 subtype is not involved in mediating the pathophysiology of type- 1 diabetic nephropathy. These discrepancies could partly be explained based on different expression profiles of PAR1 subtype in PAR2 knockout AKITA mice and STZ induced type 1 diabetic mice. However, the direct cross-talk between PAR1 and PAR2 receptors in the pathogenesis of type-1 DN needs further exploration.

\subsection{Dual blockade of PAR1 and PAR2 in type-1 DKD}

The initial studies have addressed the individual roles of PAR1 and PAR2 antagonism in an experimental model of DKD. So far, the beneficial effects of PAR1 and PAR2 blockade alone have been conclusively known to abrogate the pathological events associated with experimental diabetic nephropathy by preventing structural alterations such as glomerulosclerosis, collagen deposition, mesangial expansion and attenuating the release of pro-inflammatory and pro-fibrotic mediators [52-54,59]. Recently, attention has also been focused on inhibiting both the receptor subtypes concurrently in the development of diabetic nephropathy (Figure-02). Interestingly, an experimental study conducted by Mitsui et al [65] investigated the impact of both PAR-1 and PAR-2 inactivation in eNOS deficient type I diabetic Akita mice that is a well-characterized animal model of renal complication underlying diabetes [63]. These eNOS depleted diabetic mice present distinct features of progressive DN, particularly elevated mean blood glucose and creatinine levels, pronounced albuminuria, mesangial expansion, $\mathrm{CD} 68^{+}$macrophage infiltration and collagen type IV deposition in glomeruli leading to deleterious nephropathic changes. This eventually resulted into critical upregulation of pro-inflammatory mediators such as TNF- $\alpha$, MMP-1, EGF-like module-containing mucin-like hormone 
receptor-like 1 (Emr1) mainly expressed on murine macrophages and significantly enhanced the expressions of TGF- $\beta$, plasminogen activator inhibitor-1 ( Pai-1), Collagen type-1 (Col1) which contributes to the development of tissue fibrosis. In this study, diabetic mice were administered with PAR1 inhibitor E5555 $(60 \mathrm{mg} / \mathrm{kg} /$ p.o $)$ and PAR2 antagonist FSLLRY-NH2 $(60 \mathrm{mg} / \mathrm{kg} /$ i.p $)$ either alone or in combination continually for four weeks. Although, it was observed that co-administration of E5555 + FSLLRY-NH2 did not improve creatinine and glucose levels in diabetic rats but appeared to produce a marked decrease in albuminuria, collagen IV deposition that halted the fibrotic events as confirmed by downregulation of TGF- $\beta$, Pai-1, Col1 gene expressions. The upregulation of these genes has pathological implications in glomerulosclerosis and renal interstitial fibroma [65]. Aside from this, the combination E5555 + FSLLRY-NH2 also diminished pro-fibrotic biomarker Emr1 resulting in reduced infiltration of CD68 positive macrophage cells, TNF- $\alpha$, MMP-1. It is worth highlighting that synergistic effects of dual blockade of PAR subtypes are more prominent as compared to their individual effects in DKD. Additionally, in consideration of the wide localization of PAR subtypes on endothelial cells [2, 28-30] authors examined the independent and additive effects of PAR1 agonist (TFLLR-NH2) and PAR2 agonist (2f-LIGRLO) in cultured human endothelial cells in vitro. This treatment resulted in a remarkable rise in mRNA expression of macrophage chemoattractant protein 1 (MCP-1) or plasminogen activator inhibitor (PAI-1). The role of MCP-1 and PAI-1 has been well documented in triggering the migration of leukocytes and acts as a fibrosis-promoting molecule collectively leading to degrading renal functions [66, 67]. Apparently, PAR1 agonist-mediated increase was found to be completely subsided when Bay11-708 the inhibitor of NF-kB was pre-added to the endothelial cells. Whilst PAR2 agonist triggered elevation in MCP-1 and PAI-1 levels was blocked by MAPK inhibitor U-0126. In summary, it can be presumed that PAR1 and PAR2 mediated up-regulation in MCP-1 and PAI-1 expressions follow distinct mechanistic pathways in producing injury. Nevertheless, findings from the present study suggest the synergistic effects of PAR1 \& PAR2 antagonism in type-1 diabetes-induced kidney disease which is mediated by attenuating fibrosis, inflammatory cascades, and infiltration of macrophages [65]. However, the exploration of PAR1 and PAR2 additive renoprotective effects in type2 diabetes are still lacking and needs prompt investigation.

\section{Potential therapeutic effects of PAR2 in glomerular and podocyte injury}

A study has demonstrated the role of PARs in mediating podocyte injury in a puromycin aminonucleoside (PAN) rat model of nephrotic syndrome (NS) [68] Pathologically, NS contributes to podocyte damage associated with high proteinuria. The persistent rise in proteinuria is one of the common causes of ESRD [6972]. In PAN-induced nephrotic rats, the immunofluorescence histology of glomeruli showed co-localization of thrombin in podocytes, which is parallel with the proteinuria development during the disease progression. Moreover, this study revealed that inhibition of thrombin by hirudin significantly reduced the level of proteinuria as compared to control-treated nephrotic rats, which is probably by inhibition of ERK1/2 phosphorylation. From previous studies, it is evident that extracellular signal-regulated kinase (ERK) is an important sub-family of the MAPK signaling pathway, and it is mainly stimulated by growth factors and hormones. In disease conditions such as nephropathic conditions, the activated ERK is responsible for the induction of mitochondrial dysfunction, renal inflammation, and tubular apoptosis [73]. Notably, more studies have confirmed the expression of all PAR receptors in podocytes via RT-PCR and western blot techniques $[74,75]$. In addition, the study by Sharma et al [68] also revealed that in PAN induced nephrotic rats thrombin induced podocyte injury is by PAR1/PAR4 dependent manner, which is different in human podocytes (PAR3/PAR4 dependent). These findings were obtained by proximity ligation assays (PLAs), which showed cross-talk between PAR1/PAR4 and PAR3/PAR4 in cultured rat podocyte cells in presence of thrombin. Thrombin-induced podocyte injury was reduced upon pre-incubation with anti-PAR1 or antiPAR4 antibody and additionally, thrombin-dependent ERK signaling was also inhibited. On the other hand, in cultured human podocyte cells, PLA assay revealed reduced podocyte injury on pre-incubation with antiPAR3 or anti-PAR4 antibodies. Thus, these findings suggested the interactions between PAR1 and PAR4 in rat podocytes, whereas PAR3 and PAR4 in human podocytes [68].

Another study has investigated the role of PAR1 in the development of podocyte injury in a mouse model of drug-induced nephropathy (DIN) [49]. Gene expression studies showed that doxorubicin increased the 
expression of PAR1 mRNA in the isolated glomeruli, which was accompanied by increased albuminuria and also increased plasma creatinine levels. However, the administration of PAR1 antagonist, Q94 retarded the development of albuminuria and elevation of plasma creatinine levels in the DIN mice model. Additionally, Q94 treatment also prevented doxorubicin-induced glomerulosclerosis, renal oxidative stress, and also increased the immunostaining for podocin and nephrin (surface marker proteins of podocytes). Previously, studies have reported the involvement of calcium dyshomeostasis, such as persistent $\mathrm{Ca}^{2+}$ influx in the development of podocyte injury [2,76-79]. Moreover, thrombin is reported to activate PAR1 dependent calcium influx in the endothelial cells [80]. Furthermore, the addition of PAR1 antagonist (Q94) in cultured podocytes attenuated the doxorubicin-induced caspase $9 / 3$ activation and increased intracellular calcium levels in the podocytes, thus suggesting the role of PAR1 in regulating intracellular calcium signaling and apoptosis in the podocytes [49]. Thus it could be concluded that at least PAR1 might be a novel target for the protection of podocyte damage in drug-induced renal injury, however further studies are required in other drug-induced nephrotoxicity models.

The previous study has demonstrated that inhibition of PAR1 is protective against podocyte injury in drug-induced nephrotoxicity models [49]. Another study has investigated the beneficial effect of PAR2 in VEGF inhibitor-induced glomerular and podocyte injury in mice [81]. Vascular endothelial growth factor (VEGF) is a glycoprotein and is mainly expressed in the cells such as endothelial cells, podocytes, fibroblasts, macrophages, and certain tumor cells, where it is mainly responsible for maintaining homeostasis, cell proliferation, and differentiation, cell growth survival, regulation of angiogenesis and prevention of apoptosis $[82,83]$. VEGF inhibitors are used together with chemotherapy for the treatment of various metastatic cancers. However, the increased use of VEGF inhibitors in cancer patients has led to the development of renal injuries as the most common side effect. These renal injuries include proteinuria, thrombotic microangiopathy, and glomerular injury, and podocyturia [84]. Additionally, inhibition of VEGF is accompanied by hypercoagulability, and fibrin deposition in the glomeruli [85]. It was observed that inhibition of VEGF by anti-VEGF antibody at a dose of $58.6 \pm 16.4 \mu \mathrm{g} / \mathrm{mg}$ creatinine has shown no effect on urinary albumin excretion, as well as in glomerular histology in wild type mice. However, in the $\mathrm{eNOS}^{-/-}$mice anti-VEGF administration elevated the urinary albumin excretion and histological damage depicted by open capillary area. The endothelial nitric oxide synthase (eNOS) is known to mediate the proliferation and migration of endothelial cells during injury. Moreover, deletion of PAR2 subtype in eNOS ${ }^{-/-}$mice leads to further worsening of renal dysfunction and structural changes upon anti-VEGF treatment. The immunohistochemical analysis showed that deletion of PAR2 resulted in reduced immunopositive CD31 area (an endothelial marker of differentiation) in the glomeruli of VEGF inhibitor administered $\mathrm{eNOS}^{-/-}$mice, thus indicating impaired glomerular endothelial cells repair which resulted in albuminuria. Moreover, deletion of PAR2 also reduced the level of podocyte-specific protein called nephrin, podocyte foot process effacement in the VEGF inhibitor administered $\mathrm{eNOS}^{-/-}$mice, which indicated the development of podocyte cell damage. Notably, it was found out in the study that deletion of PAR2 has reduced the expression of glomerular VEGF protein expression and other pro-angiogenic factors such as VEGF-A, and Tie2 as compared to PAR2 positive VEGF inhibitor administered $\mathrm{eNOS}^{-/-}$mice. In addition, administration of VEGF inhibitor leads to a reduction in pro-angiogenic cytokines Ccl2, Ccr2, Cxcl1, and Cxcr2 release in PAR2 deficient $\mathrm{eNOS}^{-/}$mice. Moreover, cell line study in human endothelial cells (EA.hy926) also showed that the addition of PAR2 agonist, 2f-LIGRLO has significantly elevated the expressions of pro-angiogenic factors such as VEGF-A via MAPK and PI3K signaling pathways, thus indicating the crosstalk between PAR and growth factors. Thus, PAR2 regulates the expression of growth-promoting cytokines which induces repair and attenuates damage, thus PAR2 deficiency is partially responsible for inducing renal damage during anti-angiogenic inhibitor therapy and thus PAR levels should be carefully monitored in cancer patients undergoing anti-VEGF therapy.

\subsection{PAR2 mediates renal tubular epithelial inflammation via inhibition of autophagy}

A study has depicted the pathogenic role of PAR2 mediated inflammation using in-vitro cellular models and experimental obstructive renal injury models in mice [1]. In HK-2 cells up-regulation of PAR2 induced a decline in autophagy which promoted renal inflammation. These changes were attenuated by silencing the PAR2 expression which enhanced the autophagy process and subsequently lowered inflammation in 
these cells. Similar findings were confirmed in experimental unilateral obstructive injury in which higher renal inflammation (IL-1 $\beta$, TGF-1 $\beta$, MCP-1, and TNF- $\alpha$ ) was observed due to reduced autophagy markers namely (Atgs) autophagy-related genes and (LC3): Microtubule-associated protein 1A/1B-light chain 3 and increased PAR2 protein levels. Further improvement of autophagy by administering mTOR inhibitor rapamycin or PAR2 antagonist attenuated renal inflammation in the UUO model. These outcomes reveal that PAR2 activation during obstructive renal injury reduces the autophagy process and thereby enhances inflammation, cellular and tissue damage.

\subsection{PAR2 mediates glomerular injury and renal dysfunction in FSGS model}

Focal segmental glomerulosclerosis (FSGS) is a glomerular disease that is manifested as elevated proteinuria, podocyte injury, and immune cell infiltrations [86]. A study has investigated the role of PAR2 in mediating focal segmental glomerulosclerosis in drug-induced nephrotoxicity models [87]. In this study, nephropathy was induced by giving adriamycin (ADR) intravenously for six weeks which resulted in elevated PAR2 protein expression in the renal tissues along with the increased expression of phosphokinase A (PKA) and phosphokinase C (PKC). Among various signal transduction pathways, PKA and PKC are members of the cAMP-dependent serine-threonine kinase family that undergoes a series of phosphorylation and initiates a wide range of intracellular target proteins [88]. In turn, activation of these enzymes are likely to be responsible for vascular pathologies along with ECM synthesis and fibrosis, ROS generation, apoptosis, activation of monocytes, cell migration, dysregulation of cytokines accelerating inflammatory cascades in the development of nephropathy $[89,90]$. Also, past evidence suggests that direct pharmacological inhibition of PKA and PKC pathways attenuates the progression of renal injuries [91,92]. Moreover, ADR injection elevated the levels of pro-inflammatory cytokines in the renal tissues which were significantly attenuated by blocking PAR2 with FSLLRY-NH2. Notably, the elevated expression of PKA, PKC, and inflammation was attenuated upon administration of PAR2 blocker FSLLRY-NH2 (FSL). Furthermore, this study also suggested that PAR2 activation was involved in increasing the renal expression of pro-fibrotic TGF- $\beta 1$, caspase-9 responsible for apoptosis execution and desmin which is a cytoskeletal muscle-specific protein and key subunit of type III intermediate filament essential for tensile strength and structural integrity of myofibrils [93]. In kidneys, intermediate filament proteins are expressed in glomerular podocytes and desmin acts as an important marker of podocyte injury and excretion of this protein reflects heavy proteinuria as well $[94,95]$. Moreover, activation of PAR-2 down-regulated podocyte slit-diaphragm structural protein nephrin expression in the renal tissues of adriamycin injected rats. Interestingly, it was observed that administration of PAR2 blocker FSL corrected the levels of these pathological molecular mediators. Studies have reported that TGF- $\beta 1$ is a key mediator in renal inflammation and fibrosis. It also plays key roles in cell proliferation, differentiation, apoptosis, migration, and ECM production [96]. In glomerular diseases; TGF- $\beta 1$ is secreted by mesangial cells and is stored and transported to the podocyte surface where it is responsible for mediating inflammation, apoptosis, and podocyte injury via activating downstream signaling pathways such as Smad, MAPK, ERK, and PI3K [97-99]. Thus, in the same study, further investigations were conducted on TGF- $\beta 1$ treated cultured podocyte cells and it was observed that there was an increase in the level of the caspase- 9 enzyme, indicating podocyte apoptosis along with depleted nephrin and elevated desmin levels. However, administration of PAR2 blocker in podocyte cell line has corrected the altered caspase-9, nephrin, and desmin levels, thus indicating the involvement of PAR2 in mediating the TGF- $\beta 1$ induced podocyte damage. Histological studies also showed that administration of adriamycin has to lead to glomerular injury as manifested by the expansion of the mesangial matrix. Also in adriamycin injected rats elevated urinary proteins and serum creatinine levels, together with increased kidney weight to body weight ratio were noted which are important markers of glomerular injury and hypertrophy. However, all these manifestations were attenuated by the administration of the PAR2 blocker. This study clearly suggested that blocking of PAR2 is beneficial in the prevention of focal segmental glomerulosclerosis by suppression of pro-inflammatory cytokines release and TGF- $\beta 1$ inactivation. It is worth mentioning here that presently the treatment for FSGS relies on ACE inhibitors or ARBs which may not completely block the development of kidney diseases in FSGS patients $[100,101]$. Thus it is important to further investigate the therapeutic potential of PAR2 in other FSGS models. 


\section{Possible role of PAR2 blockade in sepsis associated kidney injury}

Sepsis is a life-threatening condition that might involve the amplified immune response of the body towards the invaded pathogen resulting in multiple organ failures including AKI [102]. In general, it appears that the early phase of sepsis follows dramatic hyper-responsiveness towards pro-and anti-inflammatory cytokines that are liberated in the blood circulation, and exposure of local adhesion receptors to surface of activated endothelial cells resulting in platelet aggregation, microthrombi formation accompanied with enhanced recruitment of immune cells $[103,104]$. However, the later stage of sepsis is characterized by immunosuppression of the immune system [105]. Lipopolysaccharide (LPS), mainly produced by gram-negative bacteria, is one of the widely used toxins to provoke an immune response that initiates kidney injury [106]. Endothelin-1 (ET-1) is an important vasoconstrictor peptide that is produced abundantly by the segments of the nephron mainly by mesangial cells, juxtaglomerular cells, renal endothelial, and principle cells of collecting duct and also by tubular region [107]. Up-regulation of renal endothelin-1 level leads to renal injury mainly by damaging podocytes, also promoting ER-stress and apoptosis induced tubular injury [108]. Specifically, the role of ET-1 has been shown to be pivotal in the inflammatory response involved in endotoxemia-related AKI. Notably, a study has investigated the effects of PAR2 blockade in lipopolysaccharide (LPS) induced elevation in the endothelin-1 peptide. (Figure-03) [109-111]. In the endotoxemic rat model [109], LPS was intraperitoneally administered as a single dose of $15 \mathrm{mg} / \mathrm{kg}$. This toxin challenge resulted in altered hemodynamic and impaired renal functions as depicted by reduced mean blood pressure and gradual increase in creatinine and BUN in the serum when observed at $1 \mathrm{hr}, 3 \mathrm{hr}, 6 \mathrm{hr}$, and $10^{\text {th }} \mathrm{hr}$. Furthermore, both serum and tissue levels of iNOS, TNF- $\alpha$, and ET-1 expressions were found to be elevated during the initial 1 and 3 hours followed by a significant decline in these levels in later hours of study after LPS administration. Moreover, the histopathological analysis showed focal tubular dilation accompanied by mild swelling and change in thickness of epithelial cells after LPS administration, which are indications of a septic kidney injury. Notably, administration of PAR2 blocker peptide (sc-9278 P) 30 minutes prior to LPS infusion could not normalize the renal dysfunction in LPS induced endotoxemic rats as depicted by unchanged levels of elevated serum creatinine and BUN levels after $3 \mathrm{hr}$. However, PAR2 blockade has effectively reduced the elevated renal tissue level of ET-1 and TNF- $\alpha$ levels, and also iNOS protein expression after 3 hours of sc-9278 P in LPS subjected rats [109]. This clearly suggested that PAR2 contributes to LPS induced renal dysfunction partly by the production of vasoconstrictive peptide ET-1, iNOS, and inflammatory cytokines release by possibly activating the NO pathway. However, PAR2 inhibition is not sufficient to attenuate functional alterations in septic rats perhaps due to a lack of binding specificity for renal tubular regions.

\section{PAR4 as a dual player in acute kidney injury}

Acute kidney injury (AKI) is one of the most common complications in hospitalized patients with an increased risk of mortality [112]. AKI can be contributed by various factors such as renal ischemia-reperfusion (I/R), with the activation of the coagulation system and inflammatory processes resulting in renal tissue remodeling and dysfunction [70,71]. Previously, studies revealed that PAR4 is present in both mice and human podocytes and also in proximal tubular epithelial cells [53,113]. Jansen et al [114] has investigated the role of PAR4 in the renal I/R injury model. In this study, post-renal IR insult resulted in up-regulation of PAR 4 gene expression in WT mice. However, it was observed that renal I/R injury resulted in the production of thrombin protease in both the WT and PAR4 knockout mice subjected to I/R injury. In addition, the expression of renal injury markers, KIM-1 and NGAL remained up-regulated in PAR 4 knockout mice post I/R injury insult, and also protein cast formation was evident in the tubular lumen. Previous studies have reported that inflammation is implicated in the pathology of renal I/R injury [70]. Jansen et al [114] in their study has demonstrated that PAR4 deletion following I/R injury decreased the neutrophil accumulation in renal tissue without having any impact on the pro-inflammatory cytokines, monocyte chemoattractant protein 1(MCP1), or keratinocyte-derived chemokine expression. However, renal I/R injury in PAR4 absence resulted in podocyte effacement which produced proteinuria. As a whole PAR4 has exhibited a dual role in mediating renal I/R injury, as it has facilitated the progression of I/R induced renal injury by promoting neutrophil invasion and in contrast also responsible for maintaining the renal filtration barrier integrity. The observed discrepancies related to distinct effects of PAR4 on renal pathological outcomes in the I/R model could be 
explained by the fact that PAR4 triggers leukocyte recruitment during the diseased conditions, but might exhibit distinct effects on renal tissue [76]. Furthermore, the findings pertaining to the distinct effects of PAR4 subtype during I/R injury need to be confirmed in other renal disease models.

\section{Summary}

Activation of PARs is responsible for the progression of diabetic nephropathy. In STZ induced type-1 diabetic mice, thrombin-dependent PAR1 activation aggravated the progression of diabetic nephropathy and its inhibition appeared to be nephroprotective. But in the case of type-2 diabetic kidney diseases, PAR1 inhibition failed to normalize the kidney dysfunction although it decreased the blood glucose levels. Strikingly in STZ induced diabetic nephropathic model, deletion of PAR2 led to increased mesangial expansion which happened to be due to increased compensatory renal PAR1 expression. Notably, Par-2 blockade was sufficient to attenuate kidney disease in AKITA mice a type-2 diabetes model. It appears that PAR-1 has a direct role in the regulation of renal perfusion and glomerular filtration rate and thus interference with its activation might counter the renal hemodynamic impairments which are encountered in the early period of type-1 diabetes. On the other hand, the PAR-2 receptor is a known regulator of inflammatory mediators which might be involved in the induction of glomerular and tubular injury in type-2 diabetes. Therefore inhibition of PAR-2 can be considered as an effective strategy for ameliorating the pathogenesis of type-2 diabetic kidney diseases. Though dual PAR blockade therapy has emerged as a promising therapy, in this case, a complete understanding of the role of PAR1 and PAR2 in different diabetic kidney diseases models needs to be done. It has been observed that in a renal I/R injury model, PAR4 exhibited a dual role, as the up-regulation of PAR4 exacerbated the I/R induced renal damage while maintaining the renal filtration barrier. Reasonably these effects might be explained based upon the distinct physiological and pathological influences of PAR-4 subtype in kidneys. Notably, both PAR-1 and PAR-2 have proven efficacy against the drug-induced nephrotoxicities in rodent models but the non-availability of oral inhibitors for PAR-2 and other subtypes poses a challenge to its translational application in the management of drug-associated renal injury. Limited evidence also suggests that targeting the PAR-1/4 subtypes could abolish experimentally induced podocyte injury but more investigations targeting other PAR subtypes in these set of diseases are highly desirable. Lastly, some hope has emerged regarding the anti-inflammatory potential of PAR-2 blocker therapy against renal inflammation in LPS induced sepsis model but it failed to improve various renal functional parameters. Therefore, exploring the protective effects of other PAR subtypes inhibitors in AKI associated with sepsis is much required. Nevertheless, it is well evident that PARs have a pivotal role in the development and progression of diverse renal injuries and once we answer the existing experimental and therapeutic challenges then their clinical potential could be unraveled in near future.

\section{Data availability statement}

Data sharing is not applicable to this article because no new data were created or analyzed in this study.

\section{Consent for publication}

The respective authors have declared their consent for the publication of this article.

\section{Funding}

The authors disclosed that no funding or financial support was received for the publication of this article.

\section{Author contribution}

N.B and G.S designed and drafted the whole manuscript. N.B., K.G., S.M. and G.S. equally contributed to the writing of this manuscript. K.G worked out the figures and tabular data. S.M and G.S supervised and analyzed each section of the manuscript. All authors agreed to the final version of the manuscript.

\section{Acknowledgments}

The authors thank Mr. Praveen Garg, Chairman and Prof. (Dr) G. D. Gupta, Director cum Principal, ISF College of Pharmacy, Moga, Punjab for their continuous support and encouragement. 


\section{Conflict of Interest}

The authors declare that they have no potential conflicts of interest related to the contents of this article.

\section{References}

1. Du C, Zhang T, Xiao X, Shi Y, Duan H, Ren Y. Protease-activated receptor-2 promotes kidney tubular epithelial inflammation by inhibiting autophagy via the PI3K/Akt/mTOR signalling pathway. Biochemical Journal. 2017 Aug 15; 474 (16):2733-47. https://doi.org/10.1042/bcj20170272

2. Palygin O, Ilatovskaya DV, Staruschenko A. Protease-activated receptors in kidney disease progression. American Journal of Physiology-Renal Physiology. 2016 Dec 1; 311 (6):F1140-4. https://doi.org/10.1152/ajprenal.00460.2016

3. Ossovskaya VS, Bunnett NW. Protease-activated receptors: contribution to physiology and disease. Physiological reviews. 2004 Apr; 84(2):579-621. https://doi.org/10.1152/physrev.00028.2003

4. Waasdorp M, Duitman J, Florquin S, Spek CA. Protease-activated receptor-1 deficiency protects against streptozotocin-induced diabetic nephropathy in mice. Scientific reports. 2016 Sep 13; 6(1):1-0. https://doi.org/10.1038/srep33030

5. Isermann B, Vinnikov IA, Madhusudhan T, Herzog S, Kashif M, Blautzik J, Corat MA, Zeier $\mathrm{M}$, Blessing E, Oh J, Gerlitz B. Activated protein C protects against diabetic nephropathy by inhibiting endothelial and podocyte apoptosis. Nature medicine. 2007 Nov; 13(11):1349-58. https://doi.org/10.1038/nm1667

6. Anil Kumar P, Welsh GI, Saleem MA, Menon RK. Molecular and cellular events mediating glomerular podocyte dysfunction and depletion in diabetes mellitus. Frontiers in endocrinology. 2014 Sep 25; 5:151. https://dx.doi.org/10.3389\%2Ffendo.2014.00151

7. Grandaliano G, Di Paolo S, Monno R, Stallone G, Ranieri E, Pontrelli P, Gesualdo L, Schena FP. Protease activated receptor and plasminogen activator inhibitor 1 EXPRESSION IN CHRONIC ALLOGRAFT NEPHROPATHY: THE ROLE OF COAGULATION AND FIBRINOLYSIS IN RENAL GRAFT FIBROSIS1. Transplantation. 2001 Oct 27; 72(8):1437-43. https://doi.org/10.1097/00007890-200110270-00018

8. Coresh J, Selvin E, Stevens LA, Manzi J, Kusek JW, Eggers P, Van Lente F, Levey AS. Prevalence of chronic kidney disease in the United States. Jama. 2007 Nov 7; 298(17):2038-47. https://doi.org/10.1001/jama.298.17.2038

9. Chu AJ. Tissue factor, blood coagulation, and beyond: an overview. International journal of inflammation. 2011 Sep 20; 2011. https://doi.org/10.4061/2011/367284

10. Rondeau E, Vigneau C, Berrou J. Role of thrombin receptors in the kidney: lessons from PAR1 knock-out mice. Nephrology Dialysis Transplantation. 2001 Aug 1; 16(8):1529-31. https://doi.org/10.1093/ndt/16.8.1529

11. Mercer PF, Chambers RC. Coagulation and coagulation signalling in fibrosis. Biochimica et Biophysica Acta (BBA)-Molecular Basis of Disease. 2013 Jul 1; 1832(7):1018-27. https://doi.org/10.1016/j.bbadis.2012.12.013

12. Waasdorp M, Florquin S, Duitman J, Spek CA. Pharmacological PAR-1 inhibition reduces blood glucose levels but does not improve kidney function in experimental type 2 diabetic nephropathy. The FASEB Journal. 2019 Oct; 33 (10):10966-72. http://dx.doi.org/10.1096/fj.201900516R

13. Brosius FC. New insights into the mechanisms of fibrosis and sclerosis in diabetic nephropathy. Reviews in Endocrine and Metabolic Disorders. 2008 Dec 1; 9(4):245. https://doi.org/10.1007/s11154-0089100-6

14. Gieseler F, Ungefroren H, Settmacher U, Hollenberg MD, Kaufmann R. Proteinase-activated receptors (PARs)-focus on receptor-receptor-interactions and their physiological and pathophysiological impact. Cell Communication and Signaling. 2013 Dec; 11(1):1-26. https://doi.org/10.1186/1478-811x-11-86

15. Packham DK, Alves TP, Dwyer JP, Atkins R, De Zeeuw D, Cooper M, Shahinfar S, Lewis JB, Heerspink HJ. Relative incidence of ESRD versus cardiovascular mortality in proteinuric type 2 diabetes and nephropathy: results from the DIAMETRIC (Diabetes Mellitus Treatment for Renal Insufficiency Consortium) database. American Journal of Kidney Diseases. 2012 Jan 1; 59(1):75-83. 
https://doi.org/10.1053/j.ajkd.2011.09.017

16. Lin C, Duitman J, Daalhuisen J, ten Brink M, von der Thüsen J, van der Poll T, Borensztajn K, Spek CA. Targeting protease activated receptor-1 with P1pal-12 limits bleomycin-induced pulmonary fibrosis. Thorax. 2014 Feb 1; 69(2):152-60. https://doi.org/10.1136/thoraxjnl-2013-203877

17. Rullier A, Gillibert-Duplantier J, Costet P, Cubel G, Haurie V, Petibois C, Taras D, Dugot-Senant N, Deleris G, Bioulac-Sage P, Rosenbaum J. Protease-activated receptor 1 knockout reduces experimentally induced liver fibrosis. American Journal of Physiology-Gastrointestinal and Liver Physiology. 2008 Jan; 294(1):G226-35. https://doi.org/10.1152/ajpgi.00444.2007

18. Duitman JW, Ruela-de-Sousa RR, Shi K, de Boer OJ, Borensztajn KS, Florquin S, Peppelenbosch MP, Spek CA. Protease activated receptor-1 deficiency diminishes bleomycin-induced skin fibrosis. Molecular Medicine. 2014 Jan 1; 20(1):410-6. https://doi.org/10.2119/molmed.2014.00027

19. Chertow GM, Burdick E, Honour M, Bonventre JV, Bates DW. Acute kidney injury, mortality, length of stay, and costs in hospitalized patients. Journal of the American Society of Nephrology. 2005 Nov 1; 16(11):3365-70. https://doi.org/10.1681/asn.2004090740

20. Macfarlane SR, Seatter MJ, Kanke T, Hunter GD, Plevin R. Proteinaseactivated receptors. Pharmacological reviews. 2001 Jun 1; 53(2):245-82. https://pubmed.ncbi.nlm.nih.gov/11356985/\#: :text=2001\%20Jun\%3B53(2)\%3A245-82.

21. Grandaliano G, Pontrelli P, Cerullo G, Monno R, Ranieri E, Ursi M, Loverre A, Gesualdo L, Schena FP. Protease-activated receptor-2 expression in IgA nephropathy: a potential role in the pathogenesis of interstitial fibrosis. Journal of the American Society of Nephrology. 2003 Aug 1; 14(8):2072-83. https://doi.org/10.1097/01.asn.0000080315.37254.a1

22. Watanabe M, Oe Y, Sato E, Sekimoto A, Sato H, Ito S, Takahashi N. Protease-activated receptor 2 exacerbates cisplatin-induced nephrotoxicity. American Journal of Physiology-Renal Physiology. 2019 Apr 1; 316(4):F654-9. https://doi.org/10.1152/ajprenal.00489.2018

23. Lei Y, Ehle B, Kumar SV, Müller S, Moll S, Malone AF, Humphreys BD, Andrassy J, Anders HJ. Cathepsin $\mathrm{S}$ and protease-activated receptor-2 drive alloimmunity and immune regulation in kidney allograft rejection. Frontiers in Cell and Developmental Biology. 2020 Jun 5; 8:398. https://doi.org/10.3389/fcell.2020.00398

24. Jin M, Yang HW, Tao AL, Wei JF. Evolution of the protease-activated receptor family in vertebrates. International journal of molecular medicine. 2016 Mar 1; 37(3):593-602. https://doi.org/10.3892/ijmm.2016.2464

25. O'Brien PJ, Molino M, Kahn M, Brass LF. Protease activated receptors: theme and variations. Oncogene. 2001 Mar; 20(13):1570-81. https://doi.org/10.1038/sj.onc.1204194

26. Heuberger DM, Schuepbach RA. Protease-activated receptors (PARs): mechanisms of action and potential therapeutic modulators in PAR-driven inflammatory diseases. Thrombosis journal. 2019 Dec; 17(1):1-24. https://doi.org/10.1186/s12959-019-0194-8

27. Pan H, Boucher M, Kaunelis D. PAR-1 antagonists: an emerging antiplatelet drug class. http://www.ncbi.nlm.nih.gov/books/nbk391027/

28. Hollenberg MD, Wijesuriya SJ, Gui Y, Loutzenhiser R. Proteinase-activated receptors (PARs) and the kidney. Drug development research. 2003 Sep; 60(1):36-42.

29. Gui Y, Loutzenhiser R, Hollenberg MD. Bidirectional regulation of renal hemodynamics by activation of PAR1 and PAR2 in isolated perfused rat kidney. American Journal of Physiology-Renal Physiology. 2003 Jul; 285(1):F95-104. https://doi.org/10.1152/ajprenal.00396.2002

30. Vesey DA, Hooper JD, Gobe GC, Johnson DW. Potential physiological and pathophysiological roles for protease-activated receptor-2 in the kidney. Nephrology. 2007 Feb; 12(1):36-43. https://doi.org/10.1111/j.1440-1797.2006.00746.x

31. Saleem MA. What is the role of soluble urokinase-type plasminogen activator in renal disease? Nephron. 2018; 139:334-41. https://doi.org/10.1159/000490118

32. Sappino AP, Huarte J, Vassalli JD, Belin D. Sites of synthesis of urokinase and tissue-type plasminogen activators in the murine kidney. The Journal of clinical investigation. 1991 Mar 1; 87(3):962-70. https://doi.org/10.1172/jci115104 
33. Zhang G, Eddy AA. Urokinase and its receptors in chronic kidney disease. Frontiers in bioscience: a journal and virtual library. 2008 May 1; 13:5462. https://doi.org/10.2741/3093

34. Cumming AD, Lambie AT. Urinary kallikrein excretion in chronic renal failure: relationship to blood pressure and the acute effect of captopril. Renal failure. 1987 Jan 1; 10(3-4):161-7. https://doi.org/10.3109/08860228709047651

35. Jaffa AA, Miller DH, Bailey GS, Chao J, Margolius HS, Mayfield RK. Abnormal regulation of renal kallikrein in experimental diabetes. Effects of insulin on prokallikrein synthesis and activation. The Journal of clinical investigation. 1987 Dec 1; 80(6):1651-9. https://doi.org/10.1172/jci113254

36. Heydarigoojani M. Thrombin receptor activating peptide-6 (TRAP-6) promotes human umbilical vein endothelial cells proliferation (Doctoral dissertation, Wien). http://hdl.handle.net/20.500.12708/2741

37. Chu AJ. Tissue factor, blood coagulation, and beyond: an overview. International journal of inflammation. 2011 Sep 20; 2011. https://doi.org/10.4061/2011/367284

38. Small M, Lowe GD, MacCuish AC, Forbes CD. Thrombin and plasmin activity in diabetes mellitus and their association with glycaemic control. QJM: An International Journal of Medicine. 1987 Dec 1; 65(3):1025-31. https://pubmed.ncbi.nlm.nih.gov/2971234/\#: : :text=1987\%20Dec\%3B65 (248) $\% 3 \mathrm{~A} 1025-31$.

39. VR SK, Darisipudi MN, Steiger S, Devarapu SK, Tato M, Kukarni OP, Mulay SR, Thomasova D, Popper B, Demleitner J, Zuchtriegel G. Cathepsin S cleavage of protease-activated receptor-2 on endothelial cells promotes microvascular diabetes complications. Journal of the American Society of Nephrology. 2016 Jun 1; 27 (6):1635-49. https://doi.org/10.1681/asn.2015020208

40. Bertog M, Letz B, Kong W, Steinhoff M, Higgins MA, Bielfeld-Ackermann A, Fromter E, Bunnett NW, Korbmacher C. Basolateral proteinase-activated receptor (PAR-2) induces chloride secretion in M-1 mouse renal cortical collecting duct cells. The Journal of Physiology. 1999 Nov 15; 521(Pt 1):3. https://dx.doi.org/10.1111\%2Fj.1469-7793.1999.00003.x

41. Morla L, Brideau G, Fila M, Crambert G, Cheval L, Houillier P, Ramakrishnan S, Imbert-Teboul M, Doucet A. Renal proteinase-activated receptor 2, a new actor in the control of blood pressure and plasma potassium level. Journal of Biological Chemistry. 2013 Apr 5; 288(14):10124-31.

42. Vesey DA, Cheung CW, Kruger WA, Poronnik P, Gobe G, Johnson DW. Thrombin stimulates proinflammatory and proliferative responses in primary cultures of human proximal tubule cells. Kidney international. 2005 Apr 1; 67(4):1315-29.

43. Coelho AM, Ossovskaya V, Bunnett NW. Proteinase-activated receptor-2: physiological and pathophysiological roles. Current Medicinal Chemistry-Cardiovascular \& Hematological Agents. 2003 Mar 1; 1(1):61-72. https://doi.org/10.2174/1568016033356715

44. Steinhoff M, Buddenkotte J, Shpacovitch V, Rattenholl A, Moormann C, Vergnolle N, Luger TA, Hollenberg MD. Proteinase-activated receptors: transducers of proteinase-mediated signaling in inflammation and immune response. Endocrine reviews. 2005 Feb 1; 26(1):1-43. https://doi.org/10.1210/er.2003-0025

45. Chu AJ. Role of tissue factor in thrombosis. Coagulation-inflammation-thrombosis circuit. Front Biosci. 2006 Jan 1; 11(1):256. https://doi.org/10.2741/1796

46. Alicic RZ, Rooney MT, Tuttle KR. Diabetic kidney disease: challenges, progress, and possibilities. Clinical Journal of the American Society of Nephrology. 2017 Dec 7; 12 (12):2032-45. https://doi.org/10.2215/cjn.11491116

47. Wei PZ, Szeto CC. Mitochondrial dysfunction in diabetic kidney disease. Clinica Chimica Acta. 2019 Sep 1; 496:108-16. https://doi.org/10.1016/j.cca.2019.07.005

48. Carr ME. Diabetes mellitus: a hypercoagulable state. Journal of Diabetes and its Complications. 2001 Jan 1; 15(1):44-54. https://doi.org/10.1016/s1056-8727(00)00132-x

49. Guan Y, Nakano D, Zhang Y, Li L, Liu W, Nishida M, Kuwabara T, Morishita A, Hitomi H, Mori K, Mukoyama M. A protease-activated receptor-1 antagonist protects against podocyte injury in a mouse model of nephropathy. Journal of pharmacological sciences. 2017 Oct 1; 135(2):81-8. https://doi.org/10.1016/j.jphs.2017.09.002

50. Barros JB, da Silva Santos R, da Silva Reis AA. Implication of the MAPK signalling pathway in the 
pathogenesis of diabetic nephropathy. Diabetes. 2019 Nov.

51. Komers R, Lindsley JN, Oyama TT, Cohen DM, Anderson S. Renal p38 MAP kinase activity in experimental diabetes. Laboratory investigation. 2007 Jun;87 (6):548-58. https://doi.org/10.1038/labinvest.3700549

52. Nomura K, Liu N, Nagai K, Hasegawa T, Kobayashi I, Nogaki F, Tanaka M, Arai H, Fukatsu A, Kita $\mathrm{T}$, Ono T. Roles of coagulation pathway and factor Xa in rat mesangioproliferative glomerulonephritis. Laboratory investigation. 2007 Feb; 87(2):150-60. https://doi.org/10.1038/labinvest.3700502

53. Undas A, Wiek I, Stepień E, Zmudka K, Tracz W. Hyperglycemia is associated with enhanced thrombin formation, platelet activation, and fibrin clot resistance to lysis in patients with acute coronary syndrome. Diabetes care. 2008 Aug 1; 31(8):1590-5. https://doi.org/10.2337/dc08-0282

54. Vaidyula VR, Rao AK, Mozzoli M, Homko C, Cheung P, Boden G. Effects of hyperglycemia and hyperinsulinemia on circulating tissue factor procoagulant activity and platelet CD40 ligand. Diabetes. 2006 Jan 1; 55(1):202-8. https://doi.org/10.2337/diabetes.55.01.06.db05-1026

55. Waasdorp M, Duitman J, Florquin S, Spek CA. Vorapaxar treatment reduces mesangial expansion in streptozotocin-induced diabetic nephropathy in mice. Oncotarget. 2018 Apr 24; 9(31):21655. https://doi.org/10.18632/oncotarget.25069

56. Bjornstad P, Cherney D, Maahs DM. Early diabetic nephropathy in type 1 diabetes-new insights. Current opinion in endocrinology, diabetes, and obesity. 2014 Aug; 21(4):279. https://doi.org/10.1097/med.0000000000000074

57. Fagerudd JA, Tarnow L, Jacobsen P, Stenman S, Nielsen FS, Pettersson-Fernholm KJ, Grönhagen-Riska C, Parving HH, Groop PH. Predisposition to essential hypertension and development of diabetic nephropathy in IDDM patients. Diabetes. 1998 Mar 1; 47(3):439-44. https://doi.org/10.2337/diabetes.47.3.439

58. Wolf G, Ritz E. Diabetic nephropathy in type 2 diabetes prevention and patient management. Journal of the American society of nephrology. 2003 May 1; 14(5):1396-405. https://doi.org/10.1097/01.asn.0000065639.19190.cf

59. Oe Y, Hayashi S, Fushima T, Sato E, Kisu K, Sato H, Ito S, Takahashi N. Coagulation factor $\mathrm{Xa}$ and protease-activated receptor 2 as novel therapeutic targets for diabetic nephropathy. Arteriosclerosis, thrombosis, and vascular biology. 2016 Aug; 36(8):1525-33. https://doi.org/10.1161/atvbaha.116.307883

60. Rothmeier AS, Ruf W. Protease-activated receptor 2 signaling in inflammation. In Seminars in immunopathology 2012 Jan 1 (Vol. 34, No. 1, pp. 133-149). Springer-Verlag. https://doi.org/10.1007/s00281011-0289-1

61. Chung H, Ramachandran R, Hollenberg MD, Muruve DA. Proteinase-activated receptor-2 transactivation of epidermal growth factor receptor and transforming growth factor- $\beta$ receptor signaling pathways contributes to renal fibrosis. Journal of Biological Chemistry. 2013 Dec 27; 288(52):37319-31. doi: $10.1074 /$ jbc.M113.492793

62. Pejler G, Lunderius C, Tomasini-Johansson B. Macrophages synthesize factor X and secrete factor $\mathrm{X} /$ Xa-containing prothrombinase activity into the surrounding medium. Thrombosis and haemostasis. 2000; 84 (09):429-35. DOI: 10.1055/s-0037-1614040

63. Li F, WANG CH, WANG JG, Thai T, Boysen G, Xu L, Turner AL, Wolberg AS, Mackman N, Maeda N, Takahashi N. Elevated tissue factor expression contributes to exacerbated diabetic nephropathy in mice lacking eNOS fed a high fat diet. Journal of Thrombosis and Haemostasis. 2010 Oct; 8(10):212232 https://doi.org/10.1111/j.1538-7836.2010.03976.x

64. Waasdorp M, Duitman J, Florquin S, Spek AC. Protease activated receptor 2 in diabetic nephropathy: a double edged sword. American journal of translational research. 2017; 9(10):4512.

65. Mitsui S, Oe Y, Sekimoto A, Sato E, Hashizume Y, Yamakage S, Kumakura S, Sato H, Ito S, Takahashi N. Dual blockade of protease-activated receptor 1 and 2 additively ameliorates diabetic kidney disease. American Journal of Physiology-Renal Physiology. 2020 May 1;318(5):F1067-73. doi: 10.1152/ajprenal.00595.2019.

66. Jeong BY, Uddin MJ, Park JH, Lee JH, Lee HB, Miyata T, Ha H. Novel plasminogen activa- 
tor inhibitor-1 inhibitors prevent diabetic kidney injury in a mouse model. PLoS One. 2016 Jun 3;11(6):e0157012. https://doi.org/10.1371/journal.pone.0157012

67. Zhang YY, Tang PM, Tang PC, Xiao J, Huang XR, Yu C, Ma RC, Lan HY. LRNA9884, a novel smad3dependent long noncoding RNA, promotes diabetic kidney injury in $\mathrm{db} / \mathrm{db}$ mice via enhancing MCP1-dependent renal inflammation. Diabetes. 2019 Jul 1;68(7):1485-98. https://doi.org/10.2337/db181075

68. Sharma R, Waller AP, Agrawal S, Wolfgang KJ, Luu H, Shahzad K, Isermann B, Smoyer WE, Nieman MT, Kerlin BA. Thrombin-induced podocyte injury is protease-activated receptor dependent. Journal of the American Society of Nephrology. 2017 Sep 1; 28(9):2618-30. DOI: https://doi.org/10.1681/ASN.2016070789

69. Orth SR, Ritz E. The nephrotic syndrome. New England Journal of Medicine. 1998 Apr 23;338(17):1202-11. doi: 10.1056/NEJM19980423338170\%.

70. Bonventre JV, Yang L. Cellular pathophysiology of ischemic acute kidney injury. The Journal of clinical investigation. 2011 Nov 1; 121(11):4210-21.doi: 10.1172/JCI45161.

71. Thuillier R, Favreau F, Celhay O, Macchi L, Milin S, Hauet T. Thrombin inhibition during kidney ischemia-reperfusion reduces chronic graft inflammation and tubular atrophy. Transplantation. 2010 Sep 27; 90(6):612-21. doi: 10.1097/tp.0b013e3181d72117 .

72. Kerlin BA, Ayoob R, Smoyer WE. Epidemiology and pathophysiology of nephrotic syndromeassociated thromboembolic disease. Clinical Journal of the American Society of Nephrology. 2012 Mar 1; 7(3):513-20doi: 10.2215/CJN.10131011.

73. Jo SK, Cho WY, Sung SA, Kim HK, Won NH. MEK inhibitor, U0126, attenuates cisplatin-induced renal injury by decreasing inflammation and apoptosis. Kidney International. 2005; 67(2):458-466.doi: 10.1111/j.1523-1755.2005.67102.x.

74. Madhusudhan T, Wang H, Straub BK, Gröne E, Zhou Q, Shahzad K, Müller-Krebs S, Schwenger V, Gerlitz B, Grinnell BW, Griffin JH. Cytoprotective signaling by activated protein C requires proteaseactivated receptor-3 in podocytes. Blood, The Journal of the American Society of Hematology. 2012 Jan 19;119(3):874-83. DOI: 10.1182/blood-2011-07-365973

75. Harris JJ, McCarthy HJ, Ni L, Wherlock M, Kang H, Wetzels JF, Welsh GI, Saleem MA. Active proteases in nephrotic plasma lead to a podocin-dependent phosphorylation of VASP in podocytes via protease activated receptor-1. The Journal of pathology. 2013 Apr;229(5):660-71. doi: 10.1002/path.4149.

76. Vergnolle N Protease-activated receptors as drug targets in inflammation and pain. Pharmacol Ther 2009;123(3):292-309.doi: 10.1016/j.pharmthera.2009.05.004

77. Schmidlin F, Amadesi S, Dabbagh K, Lewis DE, Knott P, Bunnett NW, Gater PR, Geppetti P, Bertrand C, Stevens ME. Protease-activated receptor 2 mediates eosinophil infiltration and hyper reactivity in allergic inflammation of the airway. The Journal of Immunology. 2002 Nov 1; 169(9):531521. doi: 10.4049/jimmunol.169.9.5315.

78. Yuan Z, Cao A, Liu H, Guo H, Zang Y, Wang Y, Wang Y, Wang H, Yin P, Peng W. Calcium uptake via mitochondrial uniporter contributes to palmitic acid-induced apoptosis in mouse podocytes. Journal of cellular biochemistry. 2017 Sep; 118(9):2809-18. doi: 10.1002/jcb.25930. Epub 2017 Apr 27.

79. Burford JL, Villanueva K, Lam L, Riquier-Brison A, Hackl MJ, Pippin J, Shankland SJ, Peti-Peterdi J. Intravital imaging of podocyte calcium in glomerular injury and disease. The Journal of clinical investigation. 2014 May 1; 124(5):2050-8. doi: 10.1172/JCI71702

80. Bonventre JV, Yang L. Cellular pathophysiology of ischemic acute kidney injury. The Journal of clinical investigation. 2011 Nov 1; 121(11):4210-21 doi: 10.1172/JCI45161.

81. Oe Y, Fushima T, Sato E, Sekimoto A, Kisu K, Sato H, Sugawara J, Ito S, Takahashi N. Proteaseactivated receptor 2 protects against VEGF inhibitor-induced glomerular endothelial and podocyte injury. Scientific reports. 2019 Feb 27; 9(1):1-1. doi: 10.1038/s41598-019-39914-8

82. Eremina V, Jefferson JA, Kowalewska J, Hochster H, Haas M, Weisstuch J, Richardson C, Kopp JB, Kabir MG, Backx PH, Gerber HP. VEGF inhibition and renal thrombotic microangiopathy. New England Journal of Medicine. 2008 Mar 13; 358(11):1129-36. doi: 10.1056/NEJMoa0707330.

83. Schrijvers BF, Flyvbjerg A, De Vriese AS. The role of vascular endothelial growth factor (VEGF) 
in renal pathophysiology. Kidney international. 2004 Jun 1;65(6):2003-17. doi: 10.1111/j.15231755.2004.00621.x.

84. Hayman SR, Leung N, Grande JP, Garovic VD. VEGF inhibition, hypertension, and renal toxicity. Current oncology reports. 2012 Aug 1; 14(4):285-94. doi: 10.1007/s11912-012-0242- $z$.

85. Muller-Deile J, Brocker V, Grunwald V, Hiss M, Bertram A, Kubicka S, Ganser A, Haller H, Schiffer M. Renal side effects of VEGF-blocking therapy. NDT plus. 2010 Apr 1; 3(2):172-5. https://doi.org/10.1093/ndtplus/sfp175

86. Rosenberg AZ, Kopp JB. Focal segmental glomerulosclerosis. Clinical Journal of the American Society of Nephrology. 2017 Mar 7; 12(3):502-17. doi: 10.2215/CJN.05960616. Epub 2017 Feb 27.

87. Wang Y, He Y, Wang M, Lv P, Wang J, Liu J. Role of protease-activated receptor 2 in regulating focal segmental glomerulosclerosis.Cellular Physiology and Biochemistry. 2017; 41(3):1147-55. doi: $10.1159 / 000464121$

88. Cass LA, Summers SA, Prendergast GV, Backer JM, Birnbaum MJ, Meinkoth JL. Protein kinase A-dependent and-independent signaling pathways contribute to cyclic AMP-stimulated proliferation. Molecular and cellular biology. 1999 Sep 1;19(9):5882-91. doi: 10.1128/MCB.19.9.5882.

89. Li J, Gobe G. Protein kinase $\mathrm{C}$ activation and its role in kidney disease. Nephrology. 2006 Oct;11(5):428-34. doi: 10.1111/j.1440-1797.2006.00673.x.

90. Shi H, Sun X, Kong A, Ma H, Xie Y, Cheng D, Wong CK, Zhou Y, Gu J. Cadmium induces epithelialmesenchymal transition and migration of renal cancer cells by increasing PGE2 through a cAMP/PKACOX2 dependent mechanism. Ecotoxicology and Environmental Safety. 2021 Jan 1;207:111480. doi: 10.1016/j.ecoenv.2020.111480.

91. Xu S, Jiang Y, Wang H, Wang Z, Liu H, Peng L, Fang Q, Deng T, You J, Zhou X, Zhang W. Cpeptide ameliorates renal injury in type 2 diabetic rats through protein kinase A-mediated inhibition of fibronectin synthesis. Biochemical and biophysical research communications. 2015 Mar 13;458(3):67480. doi: 10.1016/j.bbrc.2015.02.022.

92. Rong S, Hueper K, Kirsch T, Greite R, Klemann C, Mengel M, Meier M, Menne J, Leitges M, Susnik N, Meier M. Renal PKC- $\varepsilon$ deficiency attenuates acute kidney injury and ischemic allograft injury via TNF- $\alpha$-dependent inhibition of apoptosis and inflammation. American Journal of Physiology-Renal Physiology. 2014 Sep 15;307(6):F718-26.doi: 10.1152/ajprenal.00372.2013

93. Paulin D, Li Z. Desmin: a major intermediate filament protein essential for the structural integrity and function of muscle. Experimental cell research. 2004 Nov 15;301(1):1-7. doi: 10.1016/j.yexcr.2004.08.004.

94. Zou J, Yaoita E, Watanabe Y, Yoshida Y, Nameta M, Li H, Qu Z, Yamamoto T. Upregulation of nestin, vimentin, and desmin in rat podocytes in response to injury. Virchows Archiv. 2006 Apr;448(4):48592.doi: 10.1007/s00428-005-0134-9.

95. Maruyama M, Sugiyama H, Sada K, Kobayashi M, Maeshima Y, Yamasaki Y, Makino H. Desmin as a marker of proteinuria in early stages of membranous nephropathy in elderly patients. Clinical nephrology. 2007 Aug 1;68(2):73-80. doi: 10.5414/cnp68073.

96. Gu YY, Liu XS, Huang XR, Yu XQ, Lan HY. Diverse role of TGF- $\beta$ in kidney disease. Frontiers in cell and developmental biology. 2020 Feb 28; 8:123. doi: 10.3389/fcell.2020.00123.

97. Lee HS, Song CY. Differential role of mesangial cells and podocytes in TGF-ß-induced mesangial matrix synthesis in chronic glomerular disease. Histology and histopathology. 2009. doi: 10.14670/HH-24.901.

98. Kim TS, Kim JY, Hong HK, Lee HS. mRNA expression of glomerular basement membrane proteins and TGF- $\beta 1$ in human membranous nephropathy. The Journal of pathology. 1999 Nov; 189(3):425-30. doi: 10.1002/(SICI)1096-9896(199911)189:3<425::AID-PATH454>3.0.CO;2-6.

99. Massagué J, Blain SW, Lo RS. TGF $\beta$ signaling in growth control, cancer, and heritable disorders. Cell. 2000 Oct 13; 103(2):295-309. doi: 10.1016/s0092-8674(00)00121-5.

100. Troyanov S, Wall CA, Miller JA, Scholey JW, Cattran DC, Toronto Glomerulonephritis Registry Group: Focal and segmental glomerulosclerosis: Definition and relevance of a partial remission. J Am Soc Nephrol 16 : 1061-1068, 2005pmid:15716334 doi: 10.1681/ASN.2004070593.

101. Korbet SM: Angiotensin antagonists and steroids in the treatment of focal segmental glomerulosclero- 
sis. Semin Nephrol 23 : 219-228, 2003pmid:12704582 doi:10.1053/snep.2003.50020.

102. Gotts JE, Matthay MA. Sepsis: pathophysiology and clinical management. Bmj. 2016 May 23;353:i1585. doi: $10.1136 /$ bmj.i1585

103. Fani F, Regolisti G, Delsante M, Cantaluppi V, Castellano G, Gesualdo L, Villa G, Fiaccadori E. Recent advances in the pathogenetic mechanisms of sepsis-associated acute kidney injury. Journal of nephrology. 2018 Jun 1;31(3):351-9. doi: 10.1007/s40620-017-0452-4.

104. Rittirsch D, Flierl MA, Ward PA. Harmful molecular mechanisms in sepsis. Nature Reviews Immunology. 2008 Oct;8(10):776-87 doi: 10.1038/nri2402.

105. Otto GP, Sossdorf M, Claus RA, Rödel J, Menge K, Reinhart K, Bauer M, Riedemann NC. The late phase of sepsis is characterized by an increased microbiological burden and death rate. Critical care. 2011 Aug;15(4):1-8.doi: 10.1186/cc10332.

106. Doi K, Leelahavanichkul A, Yuen PS, Star RA. Animal models of sepsis and sepsis-induced kidney injury. The Journal of clinical investigation. 2009 Oct 1;119(10):2868-78. doi: 10.1172/JCI39421.

107. Chen M, Todd-Turla KA, Wang WH, Cao XI, Smart A, Brosius FC, Killen PD, Keiser JA, Briggs JP, Schnermann JO. Endothelin-1 mRNA in glomerular and epithelial cells of kidney. American Journal of Physiology- Renal Physiology. 1993 Oct 1;265(4):F542-50. doi: 10.1152/ajprenal.1993.265.4.F542.

108. De Miguel C, Speed JS, Kasztan M, Gohar EY, Pollock DM. Endothelin-1 and the kidney: new perspectives and recent findings. Current opinion in nephrology and hypertension. 2016 Jan; 25(1):35. doi: 10.1097/MNH.0000000000000185.

109. Jesmin S, Shimojo N, Yamaguchi N, Mowa CN, Oki M, Zaedi S, Sultana SN, Rahman A, Islam M, Sawamura A, Gando S. Effects of protease activated receptor (PAR) 2 blocking peptide on endothelin1 levels in kidney tissues in endotoxemic rat mode. Life sciences. 2014 May 2; 102(2):127-33. doi: $10.1016 / j . l f s .2014 .03 .013$

110. Mayeux PR. Pathobiology of lipopolysaccharide. Journal of toxicology and environmental health. 1997 Aug 1; 51(5):415-35. doi: 10.1080/00984109708984034.

111. Millar CG, Thiemermann C. Intrarenal haemodynamics and renal dysfunction in endotoxaemia: effects of nitric oxide synthase inhibition. British journal of pharmacology. 1997 Aug; 121(8):1824-30.doi: 10.1038/sj.bjp.0701335.

112. Lu R, MuciAo-Bermejo MJ, Armignacco P, Fang Y, Cai H, Zhang M, Dai H, Zhang W, Ni Z, Qian J, Yan Y. Survey of acute kidney injury and related risk factors of mortality in hospitalized patients in a third-level urban hospital of Shanghai. Blood purification. 2014;38(2):140-8. doi: 10.1159/000366127.

113. Madhusudhan T, Kerlin BA, Isermann B. The emerging role of coagulation proteases in kidney disease. Nature reviews nephrology. 2016 Feb; 12(2):94. doi: 10.1038/nrneph.2015.177.

114. Jansen MP, Claessen N, Larsen PW, Butter LM, Florquin S, Roelofs JJ. Dual role of protease activated receptor 4 in acute kidney injury: contributing to renal injury and inflammation, while maintaining the renal filtration barrier upon acute renal ischemia reperfusion injury. BioRxiv. 2019 Jan 1:540427. doi: https://doi.org/10.1101/540427 


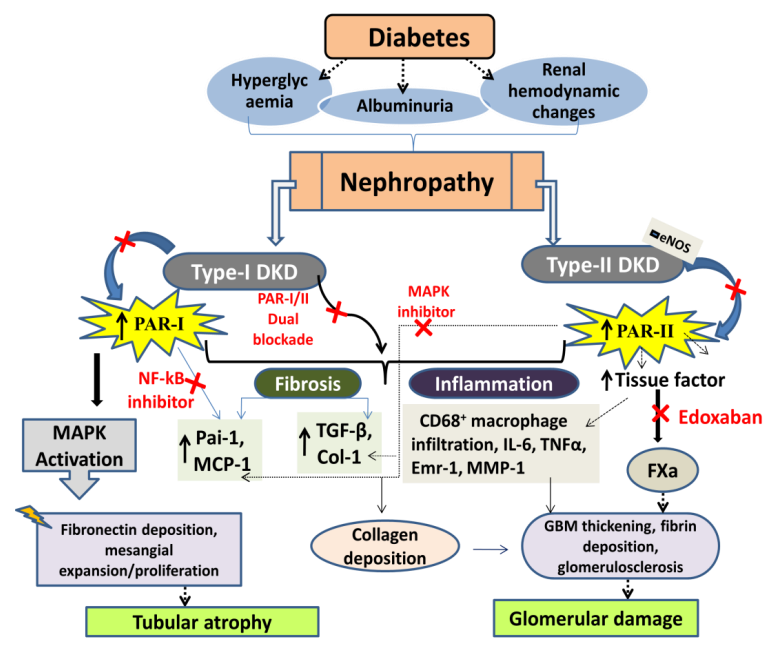

Figure 01: Role of PAR-I AND PAR-II represented against diabetic kidney disease

(DKD). Diabetes is characterized by hyperglycemia, urine albuminuria, and hemodynamic alterations that result in type- 1 and type 2 diabetic nephropathy. The level of PAR-1 has increased in type-1 DKD that primarily leads to MAPK activation causing fibrosis and tubular structural damage in nephrons. On the other hand, the level of PAR2 is increased in eNOS deficient type-2 DKD that further raises the tissue factor and in turn increases collagen deposition, pro-inflammatory, and pro-fibrotic mediators respectively. Furthermore, this results in glomerular damage in the kidneys. Note: Inhibition of all these pathogenic events has been shown in red. 


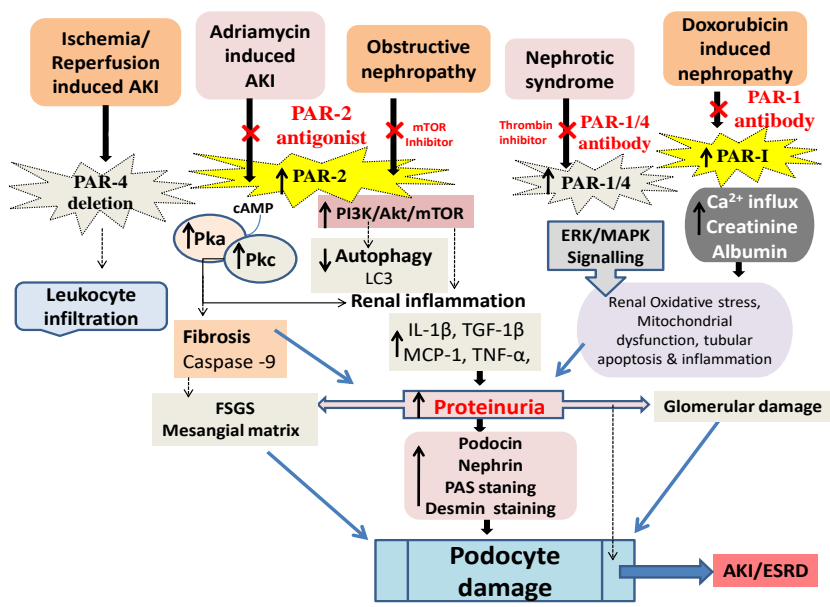

Figure 02: Role of PAR1 and PAR2 in kidney injury from different etiological basis. In I/R injury, deletion of PAR4 leads to infiltration of leukocytes. In the adriamycin-induced AKI and UUO model of rats, the levels of PAR2 were increased which resulted in reduced autophagy accompanied with increased proteinuria, inflammation, and fibrosis via upregulated $\mathrm{PKA} / \mathrm{PKC} / \mathrm{cAMP}$ signaling and $\mathrm{PI} 3 \mathrm{~K} / \mathrm{Akt} / \mathrm{mTOR}$ pathway that collectively contributed to podocyte damage. Administration of PAR2 antagonist significantly corrected these events. In nephrotic syndrome, levels of PAR-1/PAR-4 were increased via upregulated ERK/MAPK signaling. This resulted in renal oxidative stress, mitochondrial dysfunction, tubular apoptosis leading to glomerular damage and in turn podocyte injury. However, antibodies of PAR1/PAR4 and thrombin inhibitor resolved the respective pathological features. In drug-induced nephropathy, PAR1 antagonist reduced the increased levels of PAR1 along with increased calcium influx and prevented renal functional parameters that further lead to oxidative stress, glomerular damage, and podocyte damage. All these renal pathophysiological features contribute to AKI to CKD transition. 


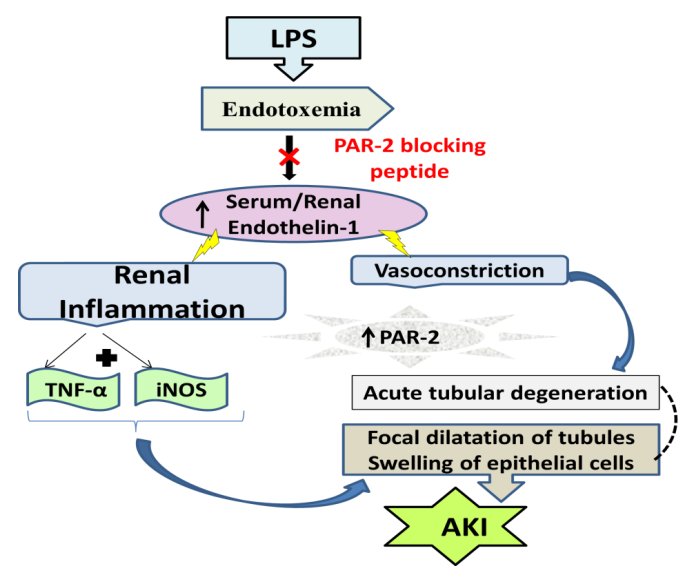

Figure 03: In the endotoxemic model of rats, LPS treatment resulted in increased expressions of endothelin in serum/tissue. This further triggered inflammation, vasoconstriction and increased PAR2 impression contributing to acute tubular degeneration, dilatation of tubular cells resulting in AKI. Administration of PAR2 blocking peptide prevented these manifestations in LPS subjected rats. 